\title{
TWO SIDED MARKETS - HOW TO GENERATE VALUE FROM THEM
}

\author{
Mani P. Sam ${ }^{1}$, Issac K. Varghese ${ }^{2}$ \\ manipsam@rajagiri.edu¹, issackv@ rajagiri.edu² \\ Rajagiri Business School, Kakanad- 68208, Ernakulam, India
}

\begin{abstract}
The article provides insights on two sided markets. Two sided markets ae gaining momentum in the economy that's relying more and more on cashless mode. It also talks about the way value is generated on platforms for both the sides. The article highlights the effect of networks on value creation. The cost management of these platforms can be done by using activity based costing. The article also throws light on the need for eliminating non value-adding activities.
\end{abstract}

Key words: Two sided markets, network effects, value creation.

Jel Classification : M20

\section{TWO SIDED MARKETS - HOW TO GENERATE VALUE FROM THEM}

Two sided markets always existed but they are becoming more prominent due to the growth of the cashless economy. A non-cash transaction involves intermediaries and a two-sided market.

A two-sided market or in general multi-sided markets are situations where the users carry out transactions through a single or multiple platforms. Every transaction may have multiple beneficiaries and the value added by the platform is dependent on the number of participants in the platform (network effect). The platforms are essential for enabling the transaction but they do not per se provide the good or service being transacted.

Value generated by platforms depends on the Network effect. Metcalfe's law (Metcalfe, B, 2013), was originally proposed for computers and telecommunication networks. However, it was found to have application in social media as well as two sided markets.

Platforms encourage both the sides to utilize them but the method of charging the two sides will be very different. It is not based on the usage or resources or the extent of utility enjoyed by the two sides. In other words the price charged may not be dependent on the incremental cost incurred in serving that side. In fact the pricing may be highly lopsided or reflect a water bed effect, cost incurred for servicing the non-paying side may get added to the price of the paying side. In certain platforms one side may get inducements or rewards rather than charges. Why? May be because the platforms exist and thrive due to the network effect (Van Alstyne, et. al., 2016).

Network effect is the phenomenon wherein a product or service (offered by a platform) gains better perceived value as more and more people avail the product or service through the platform. The marginal value added by a user is more than the existing average value. Thus, the value of the product or service to a user is directly dependent on the number of other users using it. Any multi sided market and the platforms creating them will be riding on the network effect. However, the way they treat the users will not be based on the cost of serving them or the way in which revenue accrues from 
them. Social media are the best example of the impact of network effect. Platforms where more persons are present attract more and more members.

Let us look at some of the two-sided markets.

Credit cards are a classic example. A card holder can use the card only if the merchant accepts it. If a merchant does not have the facility to accept a credit card he may lose the business to someone else. The credit card company will provide more and more swipe machines to merchants having larger number of transactions. The credit card holders are pampered by the card issuer through reward points so that they use the cards more often. They offer a uniform free credit period to all but charge a hefty fee on overdue amounts and some card issuers may even use some pressure tactics to collect the outstanding dues. Leaving aside such deviations, many persons can gain the rewards, free book keeping (account statements are free expense statements available for download in soft form as well) and free credit. However, the total cost (and a sizeable profit) is charged to the to the merchants and customers who end up with overdues. When the credit card company is able to buy group insurance at a better discount many of the card holders opt for it. The platform makes a good commission on the policies sold while the seller (insurance company) get a group policy of sizeable value. They may then create a separate login or relationship manager for this group. Renewals are the rule rather than the exception and many may even opt for auto renewal. A definite win -win situation for all.

However what is the relationship between the cost and price? Inverse, you seem to be charging what the traffic could bear? How do we arrive at the pricing for a credit card holder? We have to give reward points to retain one. So there is no direct revenue from the credit card holder. However all the merchandise the holder purchases entitles the credit card company to make revenues indirectly. The merchants are paid only after deducting the charges of the credit card company. The credit card company is also able to get deals for its card members based on the large population. It is a virtuous cycle ; more the members, better rewards and deals for the members and more members are attracted to use the card.

Given the fact that most of the credit card holders have multiple cards in their wallet the credit card companies are vying with each other to promote their cards. Many have tried cobranded cards wherein the rewards are generally borne by the partner entity and the card issuer of course gets a lower margin on the sales.

Pricing of services has always been a tricky issue and the same has become more complex with the two sided and multi sided markets. (Parker \& Van Alstyne, 2014). Many companies apply Business Intelligence tools to cull out valuable information from the database of credit card users especially their expenditure patterns. It allows them to target potential customers for loans, insurance, mutual funds and various other financial products. This two sided markets gives card holders preferential treatment? Not really though there is no cost recovery from any of the members for the card per se all those who defaults in payments pay a hefty interest. Merchants on the other hand pays for all the costs. Standard pricing models could work around a volume linked discount for the merchants. However, defaulter interest rates continue to be hefty because of the risk involved in an unsecured loan. If the higher interest rates adequately offset the risks, the issue of cards is an easy method of soliciting loans

Let us now take a closer look at reward points; the best offered may be 2 per 100 rupees spent. The reward points may not always be equated to a rupee (there are co-branded cards like CitiIOC where one reward point has Re 1 value). Generally speaking the reward points in effect have value less than a rupee. What is the cost of reward points? The cost of running the loyalty programme (rewards points have fixed 
period validity in most of the cards and it need to be managed on a real-time basis) and the cost of rewards and administration. The reward points are awarded only when an expenditure is made and hence only after the revenue is accrued from the merchant. The decision is how much to share with the card holder? Many a time direct cash back may be offered which is also direct sharing with the card holder. The following diagram gives a rough idea about the revenue sharing. It is obvious that the old dictum "The man who pays the piper calls the tune" does not apply to the revenue sharing.
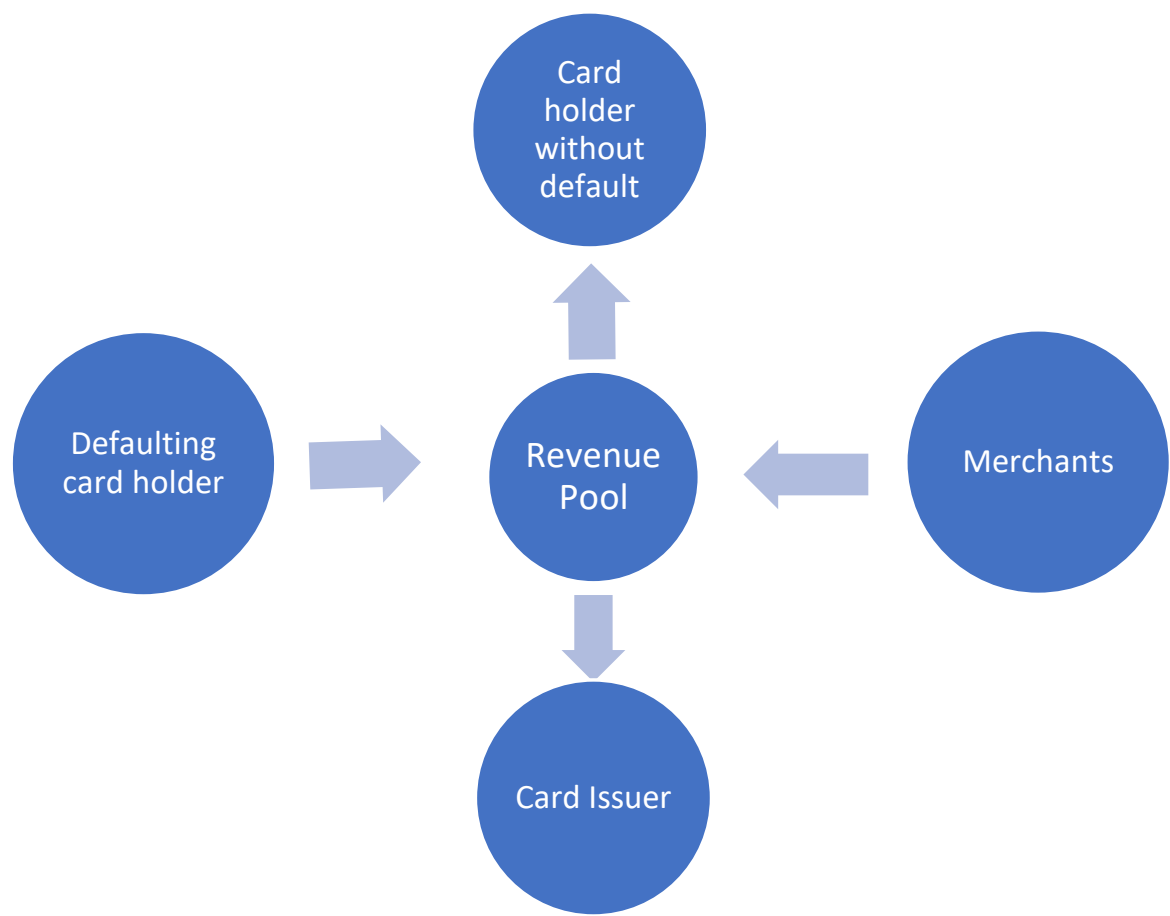

Figure 1:

The card holder who pays the bills regularly can really benefit from the free credit period and the rewards. Let us now do a sample computation: The card holder uses credit card for all his family expenses and gets free credit for 45 days. The card holder is diligent and keeps the estimated expenses in the savings account till the credit card bill is due. He has given a standing instruction for NEFTing the amount to the credit card account on the due date. He has also opened a SIP (Systematic Investment Plan0 with a liquid fund as well as a SWP (Systematic Withdrawal plan) so that on the first day of the month the SIP is activated and the SWP credits the money one day before the due date to the savings account. Let us assume a monthly expense of Rs 30,000 and liquid fund daily dividend of 5\% (after $\operatorname{tax})$.

The diligent card holder can make a tidy sum in addition to the reward points and may be able to pull out his original investment before 8 years. The fate of a person who makes default for couple of months is no different he will get into a perpetual cycle of overdue interest payment as the interest rates are higher than 36\% per annum. Banks makes major revenues from them. No reward points are given on overdue amounts. However, credit card provides easy credit to entrepreneurs and those who cannot get credit in any other way. The higher cost may be considered as the price they pay for the ease of availing credit. 
Table 1

\begin{tabular}{|c|c|c|c|c|c|c|c|c|c|c|c|c|}
\hline Month & 1 & 2 & 3 & 4 & 5 & 6 & 7 & 8 & 9 & 10 & 11 & 12 \\
\hline Deposit & 30000 & 30000 & 30000 & 30000 & 30000 & 30000 & 30000 & 30000 & 30000 & 30000 & 30000 & 30000 \\
\hline $\begin{array}{l}\text { Dividend } \\
\text { income on } \\
\text { previous } \\
\text { month's } \\
\text { deposit }\end{array}$ & 0 & 181 & 182 & 184 & 185 & 187 & 188 & 190 & 191 & 193 & 194 & 196 \\
\hline $\begin{array}{l}\text { Devidend } \\
\text { on current } \\
\text { month's } \\
\text { deposit }\end{array}$ & & 62 & 62 & 62 & 62 & 62 & 62 & 62 & 62 & 62 & 62 & 62 \\
\hline $\begin{array}{l}\text { Total } \\
\text { dividend } \\
\text { income } \\
\text { prior to } \\
\text { redemption }\end{array}$ & 0 & 242 & 244 & 245 & 247 & 248 & 250 & 251 & 253 & 254 & 256 & 257 \\
\hline Total & 30000 & 60242 & 60486 & 60732 & 60979 & 61227 & 61447 & 61728 & 61981 & 62236 & 62491 & 62749 \\
\hline Redemption & 0 & 30000 & 30000 & 30000 & 30000 & 30000 & 30000 & 30000 & 30000 & 30000 & 30000 & 30000 \\
\hline balance & 30000 & 30242 & 30486 & 30732 & 31227 & 31227 & 31477 & 31728 & 31981 & 322236 & 32491 & 31749 \\
\hline
\end{tabular}

The credit card company will only be so happy so long as the overdue interest and minimum payment are remitted every month. However, it cannot be used on a long-term basis due to the prohibitive cost. An innovator may seek this route to develop/set up a working prototype so that investors are convinced to finance the new project.

Let us now look at another ubiquitous twosided market; the e-commerce platforms. They bring the buyers and sellers together and help in reducing the sales and distribution costs. The enabling platform may interact with the credit card platform used by the buyer and the monies are normally transferred to the seller only after the buyer received the goods and accepts them. The seller may or may not be charged by the platform and the platform earns revues through advertisements as well as through services (platforms run logistics arm who picks up the item and delivers to the buyer). The buyer is the privileged party here. A buyer using a credit card to buy on the platform benefits from the reduced price as well as the reward points and the credit offered by the credit card.

Malls are another example of two sided markets. As more and more buyers came to the market more and more sellers want to keep their wares in the concerned market. Modern day malls set up the infrastructure and the entertainment and other attractions for the buyers to congregate. Sellers set up shops and pay rents or revenue share to the Mall operator. It is a major change compared to the old time Kirana stores.

Cost management of platforms and two sided markets are ideally done using Activity based costing. Activity centres are identified and costs are accumulated to the activity centres. Activity centre costs are allocated to product or services based on the actual usage. It will allow the management accountant to constantly review the cost incurred and revenue earned from different categories and tweak the prices and terms based on market conditions. Let us look at an example from the credit card and banking industry; printing of monthly statements and couriering/mailing was one of the activities which has been successfully moved to a soft copy and email mode by credit card companies. Considering the saving potential incentives were offered to those who opted for soft copy through email. Banks and Telecom service providers also have followed suit.

It is essential to identify ways and means of eliminating non-value adding activities and ABC will help us to zero in on such activities. Network effect (thanks to Metcalfe's law) ensures growing volumes for successful two sided markets. Precise analysis of activities and elements of costs associated with them becomes very critical. Identification of trends and 
patterns of costs and having an ear to the ground become essential for the management accountants. Connectivity costs continue to decline and hardware and software cost and performance follow the Moore's law. They all are going to impact the performance of two sided markets having an umbilical connection to the Internet.

\section{REFERENCES}

1. Metcalfe, B. (2013). Metcalfe's law after 40 years of ethernet. Computer, 46(12), 26-31.

2. Parker, G. G., \& Van Alstyne, M. W. (2005). Two-sided network effects: A theory of information product design. Management science, 51(10), 1494-1504.

3. Parker, Geoffrey, and Marshall W. Van Alstyne. "Platform strategy." (2014).

4. Van Alstyne, M. W., Parker, G. G., \& Choudary, S. P. (2016). Pipelines, platforms, and the new rules of strategy. Harvard business review, 94(4), 54-62. 